\title{
Enhanced Carbon Influx into TFTR Supershots
}

\author{
A. T. Ramsey, C. E. Bush, H. F. Dylla ${ }^{*}$, D. K. Owens, C. S. Pitcher ${ }^{\dagger}$,
} M. Ulrickson

\section{Princeton Plasma Physics Laboratory, Princeton University \\ Princeton, New Jersey 08543 \\ United States of America}

\begin{abstract}
Under some conditions, a very large influx of carbon into TFTR occurs during beam injection into low recycling plasmas (the Supershot regime). These carbon "blooms" result in serious degradation of plasma parameters. The sources of this carbon have been identified as hot spots on the TFTR bumper limiter at or near the last closed flux surface. Two separate temperature thresholds have been identified. One, at about $1650^{\circ} \mathrm{C}$, is consistent with radiation enhanced sublimation. The other, at about $2300^{\circ} \mathrm{C}$, appears to be thermal sublimation of carbon from the limiter. To account for the increased density caused by the blooms, near unity recycling of the carbon at the limiter by physical sputtering is required; this effect is expected from laboratory measurements, and we believe we are seeing it on TFTR. The sources of the carbon blooms are sites which have either loosely attached fragments of limiter material (caused by damage) or surfaces nearly perpendicular to the magnetic field lines. Such surfaces may have local power depositions two orders of magnitude higher than usual. The TFTR team modified the limiter during the opening of Winter 1989-90. The modifications greatly reduced the nurnber and magnitude of the blooms, so that they are no longer a problem.
\end{abstract}

\footnotetext{
* Permanent Address: Continuous Electron Beam Accelerator Facility, Newport News, Va., USA

† Permanent Address: Can’dian Fusion Fuels Technology Project, Toronto, Canada
} 


\section{INTRODUCTION}

During the 1989 run, sudden, large influxes of carbon (which we call "carbon blooms") inco TFTR Supershots [1] were observed at some time during beam injection for nearly all shots above a certain power threshold. The threshold, which varied from $20 \mathrm{MW}$ to $25 \mathrm{MW}$, depended on the condition of the limiter; in particular, on the existence of damaged or anomalously positioned limiter tiles. The same phenomenon is also observed in JET under similar conditions; the underlying cause is similar [2].

In the following sections in this paper, we shall first describe a bloom in terms of global plasma parameters, and then discuss the effect of the bloom on the study of supershot physics and the achievement of reactor-like plasmas. In Section 3, we shall present evidence that we have, indeed, identified the local sources of blooms, and discuss why these locations become sources. In Section 4, we shall present data supporting the argument that we are seeing both radiation enhanced sublimation, first observed by Roth et al. [3], and the more usual thermal sublimation of carbon which occurs at a much higher temperature. Finally, in Section 5, we shall describe operational techniques for avoiding blooms, and the effect of these techniques on plasma performance. We shall also describe the structural changes to the limiter which were performed ciuring the subsequent machine opening, and how they affected carbon blooms during the following run.

\section{THE BLOOM AND ITS EFFECTS}

On TFTR, the onset of a carbon bloom is most easily seen on the single chord visible bremsstrahlung monitor which views the plasma tangentially on the midplane. The tangency radius of the visible bremsstrahlung sightline is $R_{\tan }=1.90$ $\mathrm{m}$; the bumper limiter radius on the midplane is $R_{\mathrm{lim}}=1.65 \mathrm{~m}$. It is also easily visible on the $\mathrm{Cl}+$ emission from a 5 chord upper half-plane poloidal array of detectors.

The $\mathrm{C}^{1+}$ array views the Zeeman split multiplet centered at $6578 \AA\left(2 \mathrm{~s}^{2}\left({ }^{1} \mathrm{~S}\right) 3 \mathrm{~s}\right.$ $3 p)$. The interference filters do not admit a significant amount of the nearby and comparably bright $H_{\alpha}$ and $D_{\alpha}$ lines at $6563 \AA$ and $6561 \AA$, respectively. The sum of 
$\mathrm{H}_{\alpha}$ and $\mathrm{D}_{\alpha}$ are separately monitored with another poloidal array of detectors. Figure 1 shows the $\mathrm{C}^{1+}$ and $\mathrm{D}_{\alpha}$ profiles during a discharge which had a large bloom. The neutral beam injection begins at $3.5 \mathrm{~s}$, and the $\mathrm{C}^{1+}$ influx line increases as the overall density rises from beam fuelling. The profile is peaked about $30^{\circ}$ (measured from the plasma center) above the midplane, where the escaping particle flux is the

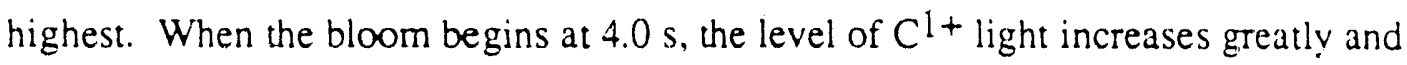
the profile shifts up in angle slightly. At the same time, the $D_{\alpha}$ brightness increases by nearly as much, and the profile shifts strongly upward from a centrally peaked distribution. This shift probably reflects a strong contribution to $\mathrm{D}$ recycling from $\mathrm{C}$ impact.

If we look at the carbon content of the plasma during the evolution of a bloom, we see an even more dramatic change. Figure 2 shows the time history of $Z_{\text {eff }}$ during another blooming shot. Before the neutral beams come on, the $Z_{\text {eff }}$ of a supershot is typically $Z_{\text {eff }}=4.5-6$, with a metal contribution of about $Z_{\text {metals }}=.2$ .5. The dominant impurity in TFTR is carbon, with very little oxygen $\left(n_{\mathrm{C}} / n_{O} \geq 10\right)$. (For a complete discussion of impurities in TFTR supershots, see Ref. [4].) When the veams turn on (at $3.0 \mathrm{~s}$ in this discharge), beam fuelling dilutes the plasma and $Z_{\text {eff }}$ drops to about 2 . At $3.4 \mathrm{~s}$, the bloom begins, and the $Z_{\text {eff }}$ rises sharply. For this shot, $Z_{\text {eff }}$ (metals $) \approx 0.5$, so the rise to $Z_{\text {eff }}=7.3$ probably reflects the $\pm 10 \%$ ( $1 \sigma$ ) error in the measurement and the fact that the full density and temperature profile information was not used in the calculation of the time dependent $Z_{\text {eff. The hirh }}$ value does show that the plasma becomes carbon dominated, and in Fig. $2 b$ we see the line average carbon density for that shot inferred from the $Z_{e f f}$.

$$
\overline{n_{C}}=\frac{n_{C} \ell}{2 a}=\frac{n_{e} \ell}{2 a}\left(\frac{Z_{e f f}-1}{30}\right),
$$

where $n_{C} \ell$ and $n_{e} \ell$ are the carbon ion and electron line integrated densities, and $a$ is the minor radius of the plasma. There is a small decrease in the carbon density when the beams turn on, probably caused by decreased carbon penetration into the core as the edge density rises. However, when the bloom begins, the carbon increases by a factor of 10 . Remember that the visible bremsstrahlung emission is heavily weighted by the density:

$$
\varepsilon(v b) \propto \frac{n_{\mathrm{e}}^{2}}{\mathrm{~T}_{\mathrm{e}}^{0.35}} Z_{\mathrm{eff}}^{0.94}
$$


(The fractional powers of $T_{e}$ and $Z_{e f f}$ reflect the charge and temperature scaling of the free-free Gaunt factor in visible bremsstrahlung emission [5].) Supershot density profiles are strongly peaked $\left(n_{e}(0) /<n_{e}\right\rangle \approx 2.5$, where $\left\langle n_{e}\right\rangle$ is the volume average density), so that the carbon density inferred from $\mathrm{Z}_{\text {eff }}$ reflects conditions in the center, unlike the $\mathrm{Cl}^{\mathrm{l}+}$ emission, which is an edge effect.

Figure 3 shows what happens to plasma performance of a discharge with $30 \mathrm{MW}$ of injected power when a bloom occurs before a shot reaches equilibrium. Figures $3 \mathrm{a}$ and $3 \mathrm{~b}$ show the midplane $\mathrm{Cl}^{\mathrm{l}+}$ emission and the vertical line integrated density at $\mathrm{R}=1.80 \mathrm{~m}$ rising at $3.9 \mathrm{~s}$. Figure $3 \mathrm{c}$ shows that the stored energy is still rising then, as is the neutron production in Fig. 3d. (The small drop in neutrons at $3.87 \mathrm{~s}$ is due to a sawtooth crash, and the level starts to climb back again before the bloom starts.)

Although some supershots reach equilibrium, with the stored energy, neutron production, and other plasma parameters constant until the heating beams turn off, frequently some deleterious activity causes degradation of the shot before this happens. MHD activity and carbon blooms are the must comrnon causes of performance degradation on TFTR. In deciding whether a bloom caused the rollover, or was incidental to (or caused by) it, one must try to correlate the bloom onset time with shot degradation. This can be difficult. Some bloom symptoms, like the increase in the visible bremsstrahlung signal, occur only after a certain amount of cross field transport has occurred. Some symptoms, like the $\mathrm{Cl}^{1+}$ emission, are more complicated than that, since singly ionized carbon is not transported in the tokamak more than a few centimeters before it is either scraped off on the limiter or ionized [6]. The $\mathrm{C}^{1+}$ radiation seen by the poloidal array is the local effect of a (usually) distant bloom. The carbon that is injected far away becomes toroidally and poloidally distributed, and is lost back through the edge to the limiter where it sputters new carbon, which in turn emits the $\mathrm{C}^{1+}$ radiation we measure. This makes determining bloom times to bette- than $\pm 50 \mathrm{~ms}$ (which is about the carbon confinement time) difficult. What is certain, however, is that even if a bloom didn't prevent a discharge from reaching its best performance, it does ultimately cause it to decay. As the power is raised, blooms will occur earlier and earlier until they do spoil performance. At $30 \mathrm{MW}$ on TFTR in the 1989 run, blooms usually were spoilers; at $37 \mathrm{MW}$ (32 MW of NBI power and $5 \mathrm{MW}$ of ICRH - our present hardware maximum) they would seriously limit our work. 


\section{BLOOMING SITES AND THEIR CAUSES}

Before we can try to find the cause of a bloom we must be certain that we are looking at the source of the bloom. On TFTR, we can see about iwo-thirds of the area of the bumper limiter as well as all of the rf limiter with the plasma television system (PTV) [7]. During an earlier run, we attributed our large blooms to cracked tiles around a recessed microwave reflector which was clearly visible on the PTV [8]. Data suggested that there may have been small blooms occurring at other sources, and examination of the tiles during the opening between that run and the 1989 run did reveal damaged tiles in the PTV blind spot. We believe the situation was simpler in the run which began in August 1989. Early in the run, we saw a damaged spot about $5 \mathrm{~cm}$ in diameter on the midplane with the PTV. The thermal load of a disruption may have caused this, since it was first observed during one of our periodic visual inspections of vacuum vessel interior early in the run shortly after a large disruption. The spot had a scaly appearance, consistent with thermal shock spallation of the polycrystalline graphite tile. Near the disruption damaged spot is the junction between two limiter tiles. At this location, one tile was about $1 \mathrm{~mm}$ higher than its neiginbor at the midplane. We believe this is due to thermally induced ratcheting of the backing plate on its mounting points. The mounting was designed to allow motion to minimize stress during periods of high temperature, but was supposed to slip back when the stress was removed. The susceptibility of this location to overheating increased in time; later in the run, we chipped and eroded its leading edge with high power supershots during a study of blooms.

With these spots in clear view of the IR camera on the PTV, which does the remote temperature measuring of TFTR's inner surface, we devoted some effort to correlating bloom onset times with the surface temperature of the damaged tiles. During our study, all supershots bloomed when the surface temperature at some location exceeded $1650 \pm 150^{\circ} \mathrm{C}$. At low powers this might occur later in the beam pulse, at higher powers it occurred earlier, but always at the same temperature. When the bloom began (signalled by a rise in VB emission), we observed very bright emission in $\mathrm{C}^{2+}$ (at $4649 \AA$ ) from the hot spot on a filter-equipped TV camera. The emission was seen streaming along the field lines from the hot spot, clearly visible for a distance of about $20 \mathrm{~cm}$.

The two sites mentioned above are not the oniy locations that bloomed during the 
run. When we run plasmas at large major radii, the last closed flux surface (LCFS) may touch the limiter surface above the midplane. At $\mathrm{R} \approx 2.6 \mathrm{~m}$, we observed t:coms not originatuig from either of the midplane sites. TFTR is divided into 20 bays by the toroidal field coils, which are designated $A$ through $T$ (see Fig. 5). We inserted the $\mathrm{C}^{2+}$ filter in the PTV and looked at the limiter where it curves out of view toward Bay $B$, since we knew from thermocouple measurements that Bay $B$ was a hot spot. (Bay B is in the PTV's blind spot, but we can see to within half a meter of so of the location on the limiter.) We observed $\mathrm{C}^{2+}$ emission strearning around the limiter into view when the bloom occurred. The streaming was about halfway up the limiter from the midplane. At the same time, we observed the $\mathrm{C}^{1+}$ profile shown in Fig. 4. The HAIFA $\mathrm{Cl}^{1+}$ poloidal array of detectors views the middle of Bay B [5]. What we see in Fig. 4 is a very localized effect. Only one channel shows a strong elevation from the bloom, and that is much greater than the rise shown in the bloom in Fig 1a. The poloidal location of this channel's sightline is near an $8 \mathrm{~cm}$ diameter hole in the limiter below an "organ pipe" (a penetration in the vacuum vessel for diagnostic access). The location of the first organ pipe above the midplane is $36^{\circ}$ above the horizontal, and the sightline of the affected channel in Fig. 4 is $33^{\circ}$ above the midplane. Thus, the $5 \mathrm{~cm}$ diameter footprint of the sightline overlaps the organ pipe in the poloidal direction.

Support for the uniqueness of these observed blooming sites is seen in Fig. 5. It shows the temperature rise in the bulk of the limiter for a given amount of energy deposited on the entire limiter during a shot. These temperature rises were measured by thermocouples in contact with the back surface of the tiles [8]. The points connected by the solid line are measured at the midplane. The unconnected point at Bay $B$ is in the upper half of the limiter at that location. The high temperature at the upper part of Bay $B$ is due to a recess at Bay $C$ for the Thomson scattering viewing dump, and the resultant higher power loading on $B$. There are two lower, but still elevated, midplane points, one at $M$ and the other at $R$. The one at $M$ was in view of the PTV, and showed minor damage. The one at $R$ was not in view.

The data shown in Fig. 5 can explain the occurrence of both bloom areas. The temperature elevation of Bay I means not only a higher power loading during normal operations, but an increased likelihood of receiving a damaging amount of heat in a disruption. The higher loading at Bay B explains why an organ pipe penetration there was a major bloom site for larger plasmas.

In summary, we believe we have identified the sites of carbon blooming because of: 1) consistent temperature threshold and bloom onset correlation, and 2) the 
observation of $\mathrm{C}^{2+}$ streaming from the site at bloom onset, and, 3) the correlation of blooming sites with elevated energy deposition.

\section{THE CAUSE OF THE BLOOMS}

Blooms occur in TFTR in reasonably well defined machine conditions. When a spot on the bumper limiter at or near the LCFS rose above $1650^{\circ} \mathrm{C}$ in a supershot $\left(\tau_{E}>2 \times \tau_{E}\right.$ (low mode)) we always saw a biuim, although in general there must certainly be a minimum hot spot size required to cause one. During the 1989 run we never saw a blcom in a low-mode discharge, although we exceeded the $1700^{\circ} \mathrm{C}$ limit. The RF antenna limiters were heated to $\mathrm{T}>1700^{\circ} \mathrm{C}$ and no bloom occurred; these limiters 'vere more than $5 \mathrm{~cm}$ outside the LCFS when these temperatures were reached. We believe this is a consistent set of conditions and we shall explain why in this section.

There are four major mechanisms which might release carbon into TFTR plasmas. We now discuss them in turn, and assess the contribution of each as a possible source of carbon in blooms.

4.1 Chemical Sputtering Chemical sputtering is a phenomenon which begins with chemical reactions on the limiter surface which yield weakly bound carbon containir.g molecules and radicals. These species can then thermally desorb or be released by particle impact (Ref. [9], p72). Subsequently, they become dissociated and ionized, and some fraction of the constituents passes into the plasma core. In particular, two major reactions result in carbon efflux from the limiter as $\mathrm{CO}$ and $\mathrm{CH}_{4}$. $\mathrm{CO}$ formation and release show no particularly strong temperature dependence, and the oxygen levels are lower in supershots where blooming occurs than in low mode shots where it doesn't. Th:e formation and rele: se of $\mathrm{CH}_{4}$ has a broad peak at $500^{\circ} \mathrm{C} \mathrm{[3],} \mathrm{which} \mathrm{is} \mathrm{much} \mathrm{lower} \mathrm{than} \mathrm{our} \mathrm{observed} \mathrm{threshold}$ temperatures. In addition, blooming occurs in shots with low, not high edge density. For these reasons, we discount chemical sputtering as a source of the bloom.

4.2 Physical Sputtering Physical sputtering is the result of energetic ions striking the limiter and knocking carbon atoms (or small groups of atoms) off the limiter surface. These particles can then get into the scrapeoff layer or into the plasma core. For the self-sputtering of $\mathrm{C}$ on graphite, this process has a threshold of about $44 \mathrm{eV}$ (Ref. [9], p61). The yield rises as the energy of the incident particle increases and as the angle of incidence becomes more grazing. At incident angles 
and edge temperatures found on TFTR, the self-sputtering yield of $\mathrm{Cn}^{\mathrm{n}} \mathrm{\text {on }} \mathrm{C}$ rises to about 1 [10]; TFTR may be near a run-away situation [11]. A detailed study of this question was done recently by Roth and coworkers [12]. Particles from physical sputtering have a broad range of energies, with the average in our case being about $10 \mathrm{eV}$. We believe that the high carbon content of supershot target plasmas (with $\mathrm{Z}_{\mathrm{eff}} \approx 5$, the carbon to deuterium ion ratio is about unity) is due to physical sputtering. (There is some evidence for this on TFTR; see Ref. [13].) However, physical sputtering yields show no dependence on the target (limiter) temperature, so that the rapid rise in carbon influx as a function of target temperature would be difficult to explain. It seems unlikely, then, that physical sputtering can explain the sharp bloom onsets, although with the yield $Y_{C C}=1$, it may help to sustain a bloom. We shall return to this later.

4.3 Sublimation Sublimation of carbon from the limiter occurs when a carbon atom has thermal energy greater than the binding energy of the material. The removal energy for a carbon atom evaporating from graphite is about $6 \mathrm{eV}$ (Ref. [9], p55). Particles which sublime from hot carbon have energies which are roughly thermal, perhaps $0.2 \mathrm{eV}$. Sublimation data from a compilation by Langley show that the rate of particle loss from a graphite surface is

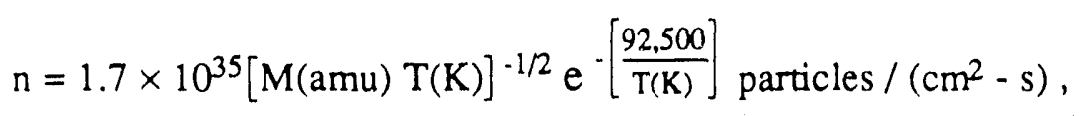

where $M$ is the mass of the particle sublimed, and the polymer ratio is $C_{1}: C_{2}: C_{3}=$ 1.0:0.5:1.6. The yield at $2000^{\circ} \mathrm{C}$, well above the bloom threshold, is only $\Gamma_{C}=1.5 \times 10^{15}$ atoms- $\mathrm{cm}^{-2}-\mathrm{s}^{-1}$; as we shall see below, this is orders of magnitude too small to fuel a bloom. However, the sublimation rate climbs to $\Gamma_{\mathrm{C}}=7 \times 10^{18}$ atoms $-\mathrm{cm}^{-2}-\mathrm{s}^{-1}$ at $2600^{\circ} \mathrm{C}$. Therefore, sublimation is unlikely to account for blooms at $1600^{\circ} \mathrm{C}$, but may be important at temperatures we have sometimes reached on TFTR. We shall discuss this further below.

4.4 Radiation Enhanced Sublimation Radiation enhanced sublimation (RES) was first observed by Roth and coworkers in 1982 [3] and described more fully by Vietzke in 1984 [14] and by Roth in 1985 [15]. A heuristic model has been developed which fits the measured data quite well [16]. The "radiation" is particle radiation; damage is caused to the carbon lattice by energetic ions leaving the plasma. In normal TFTR supershots, the energy such a particle can have ranges from about $150 \mathrm{eV}$ for a deuteron at the LCFS falling through the sheath potential to over 
$3 \mathrm{keV}$ for a $\mathrm{C}^{6+}$ ion from a few centimeters inside the core. The energy required to create an interstitial is estimated by Bohdansky to be about $40 \mathrm{eV}$ [16]. The ion impact can create one or more of these interstitial $C$ ions, which can then migrate to the surface of the limiter, or the impact can yield a loosely bound surface state to begin with. Such weakly bound atoms can evaporate (or sublime) at a lower temperature than those in a normal surface state. Vietzke and coworkers have measured the activation energy for the release of such bound atoms to be $0.78 \mathrm{eV}$ [14]. The particles evolving from RES have a near-thermal energy distribution, with energies about $0.2 \mathrm{eV}$. Bohdansky has suggested that RES might become an important carbon source mechanism at about $1600^{\circ} \mathrm{C}$, where the yield from RES has become substantially greater than from physical sputtering. As we shall argue below, this appears to be the dominant mechanism in carbon blooms at temperatures below $2300^{\circ} \mathrm{C}$.

4.5 TFTR Carbon Release Mechanisms In this section, we shall argue that the TFTR carbon blnoms occurring at about $1650^{\circ} \mathrm{C}$ are very similar to Roth's RES, with pure sublimation occurring if higher power levels result in temperatures greater than about $2300^{\circ} \mathrm{C}$. Physical sputtering does not show temperature threshold behavior, but a run-away situation could be occurring. Edge (and all other) temperatures are higher in supershots than in L-mode shots, and the energy dependence of the yields could lead to $\mathrm{Y}_{\mathrm{CC}}=1$ for the rising edge temperatures at high input powers. The close correlation between blcom onset and the temperature of hot spots on the limiter could be an artifact of correlation beiween edge temperature and limiter temperature as a whole. This is an unsatisfactory argument to make, however, since the bloom onset does not depend strictly on the energy delivered to the plasma by auxiliary heating, but varies. This variation we believe is connected with the bloom site; the thermal capacity of a damaged spot may change, but the time of blooming remains correlated with the temperature of the site. For example, the site at Bay I, which probably was caused by a disruption, bloomed much earlier in discharges just after it was discovered. During a series of $28 \mathrm{MW}$ beam heated shots, the bloom time gradually moved about $200 \mathrm{~ms}$ later in the discharge, where it stabilized. Since the damage site showed a scaly appearance (the result of carbon flakes spalled from the substrate), we believe that this delay in blooming was the result of evaporating the smaller and more quickly heated flakes away, leaving the larger flakes as the source. (Disruptions also leave layers of redeposited carbon which are poorly attached thermally to the underlying limiter tiles, and these could contribute to a blcom before they evaporate.) Such a change in 
bloom time would be more difficult to explain in terms of ordinary physical sputtering. Incidentally, we note that the arrount of carbon necessary to cause a major bloom is not large. Only $3 \mathrm{mg}$ of carbon will account for all the electrons in a high power supershot, so that even a very small flake $(5 \mathrm{~mm} \times 5 \mathrm{~mm} \times 0.5 \mathrm{~mm})$ of some $30 \mathrm{mg}$ can account for many blooms. A typical disruption burned spot may have a hundred such flakes.

Can un-enhanced sublimation account for the carbon influx from the $\mathrm{T}_{\mathrm{lim}} \approx 1600^{\circ} \mathrm{C}$ blooms? The accuracy of our infrared camera as a pyrometer was estimated to be $\pm 150^{\circ} \mathrm{C}$, which included a conservative estimate of unknown chariges in window transmission [7], but subsequent studies lead us to believe that $\pm 50^{\circ} \mathrm{C}$ is more realistic. At $1600^{\circ} \mathrm{C}$, thermal the sublimation yield of carbon varies by a factor of 10 for a $50^{\circ} \mathrm{C}$ change. Nevertheless, even allowing for this, and acknowledging some uncertainty in the parameters of sublimation, we still find ourselves several orde1. If magnitude short in the carbon influx to account for the observed rise in electron density at the temperature of bloom onset. As the temperature of parts of the limiter continues to rise during a shot, some sections become very hot $\left(\mathrm{T}_{\mathrm{lim}} \approx\right.$ $3000^{\circ} \mathrm{C}$ ) and we believe we then do see unenhanced thermal sublimation. We shall return to this later in this section.

We should point out here that the electron density rise during carbon blooms seems to be due entirely to the carbon influx. Calculations based both on the increase of $Z_{\text {eff }}$, as determined by the visible bremsstrahlung, and on charge exchange recombination spectroscopy from carbon near the plasma center show that all the added electrons observed can be accounted for by the increase in carbon ions [17].

The observation that hot $\mathrm{RF}$ limiter spots $\left(\mathrm{T}>1700^{\circ} \mathrm{C}\right)$ do not cause blooming during inner wall discharges is more likely to reflect RES with its resultant $0.2 \mathrm{eV}$ atoms than sputtering with its $10 \mathrm{eV}$ atoms. The RF limiter tips are only about one mean free path from the LCFS for a $10 \mathrm{eV}$ atom from sputtering, but about 3 mean free paths for a $0.2 \mathrm{eV}$ atom from RES.

RES is a two or three step process: interstitial creation, migration of interstitials to the surface if they were not created there, and surface desorption. We shall examine a low temperature carbon bloom, and try to construct a scenario for its developrnent. Such a shot occurred at $I_{p}=1.6 \mathrm{MA}$, with $\mathrm{a}=0.8 \mathrm{~m}$ and $\mathrm{R}=2.45 \mathrm{~m}$, and a neutral injection power of $P_{\text {beams }}=21 \mathrm{MW}$. The magnetic field on axis was $\mathrm{B}_{\mathrm{T}}=4.8$ Tesla. The temperature of the hot spot on the limiter remained below 
$2000^{\circ} \mathrm{C}$, so that pure sublimation is not expected to occur. Figure 6 shows the time derivative of the total electron number of the plasma, as measured by the 10 channel far infrared interferometer system [18]. The rate of change of the total electron number, which had been falling smoothly to zero as the plasma density approached equilibrium after beam injection began at $3.0 \mathrm{~s}$, changes to an approximately constant rate of increase of $2 \times 10^{20} \mathrm{~s}^{-1}$ at $3.6 \mathrm{~s}$. This is the bloom onset, as signalled by sharp increases in both the $\mathrm{VB}$ and $\mathrm{C}^{1+}$ emission. Although the temperature of the spot which we believe is responsible for the bloom continues to rise (see Fig. 7), the rate of increase of the number of plasma electrons is approximately constant. Since both interstitial mobility and the rate of surface desorption increase with temperature, the constant rate of increase of the total electron number suggests that the limiting factor is interstitial creation. The total power to the limiter,

$$
\mathrm{P}_{\text {limiter }}=\mathrm{P}_{\text {beams }}+\mathrm{P}_{\text {ohmic }}-\mathrm{P}_{\text {rad }}-\frac{\delta \mathrm{W}_{\text {stored }}}{\delta \mathrm{t}}
$$

remains approximately constant during the bloom, because the increase in radiated power is just balanced by the loss of energy stored in the plasma, $W_{\text {stored. }}$ This implies a constant power flux to the hotspot. The edge density can double in a bloom; see Fig. 3b. (By edge, we mean here the first $10 \mathrm{~cm}$ or so of the plasma inside the LCFS.) Together with constant power flux, the increasing density implies a drop in the edge temperature. In Fig. 8, we see the temperature of $\mathrm{C}^{1+}$ at the edge during a typical bloom; the ion temperature does indeed fall substantially. The exact of the dependence of interstitial creation rate on particle energy (through range and energy deposition profile changes) is unknown. However, to first order one expects the rate to be roughly constant above the threshold displacement energy of carbon ions to create interstitials. This is taken to be $40 \mathrm{eV}$ in the modeling work by Bohdansky et al. [16], although recent work by Nygren and coworkers on PISCES suggests that it may be as low as $20 \mathrm{eV}$ [19].

An implicit part of our argument is that the rate of overall density increase is equal to the influx from the blooming site. As we discussed in Section 4.2, at supershot edge temperatures, and with the average carbon ion impact angle onto the TFTR limiter [10], we believe that the self sputtering yield (in atoms per ion) of carbon ions on the graphite limiter is $\mathrm{Y}_{\mathrm{CC}} \approx 1$. Furthermore, the penetration efficiency of the sputtered carbon getting into the core is very high. This assumprion is discussed in more detail in the Appendix. If this is true, the limiter maintains the 
carbon content of the plasma by unity recycling, and the plasma's increase in carbon content is equal to the efflux from the hot spot.

We continue, and ask whether the blooming spot can produce enough carbon atoms to account for the increase in the plasma's core carbon. Here we have a serious problem, since we don't know what the particle flux to this atypical spot is. The release of carbon by RES is usually described in terms of a yield, since the rate of release is proportional to the incident flux over a wide range [19] despite earlier suggestions that there should be a flux dependence $[15,16]$. Roth and Bohdansky have measured $\mathrm{Y}_{\mathrm{DC}} \approx 0.3$ and $\mathrm{Y}_{\mathrm{CC}} \approx 2$ at $15000^{\circ} \mathrm{C}$ and a $60^{\circ}$ incident angle [12]. Our bloom is at $1800^{\circ} \mathrm{C}$ at the time we are considering it, and the incident angle tnay be more grazing. Nygren, on the other hand, has measured normal incidence yields about half of those of Bohdansky and Roth [19].) The Roth and Bohdansky yields, even when coupled with the assumption of unity carbon penetration efficiency from the hot spot on the last closed flux surface, require a substantial flux. At the midpoint of the bloom, with $\mathrm{Z}_{\mathrm{eff}} \approx 5$, the ratio of carbon to deuterium is $\mathrm{nC}_{\mathrm{C}} \mathrm{nD}$ $=0.67$. To get the observed net electron rise of $2 \times 10^{20} \mathrm{~s}^{-1}$ from a $10 \mathrm{~cm}^{2}$ hot spot thus requires an incident flux of $\Gamma_{\mathrm{p}}=4 \times 10^{18} \mathrm{~cm}^{-2}-\mathrm{s}^{-1}$. This is a high flux for a point on the midplane, leading to a power deposition of about $\Gamma_{\mathrm{E}}=1 \mathrm{~kW}-\mathrm{cm}^{-2}$. At this time in the discharge, the power loading averaged over the entire limiter is about $50 \mathrm{~W}-\mathrm{cm}^{-2}$. A much more detailed examination would be required to tell if a raised tile edge near the midplane could see an enhancement of the average power loading of 20 , although an increase by an order of magnitude due to the tile edge elevation above its normal level would not be surprising, and an error of a factor of 2 in our value of the RES yields is not out of the question.

The situation is a little less ambiguous when we consider a shot which shows evidence of both types of bloom. Figure 9 shows data from a shot where the temperature of a damaged spot nearly reached $3000^{\circ} \mathrm{C}$. Figure 9 a shows the visible bremsstrahlung radiation. Beam injection begins at $3.0 \mathrm{~s}$, and the visible bremsstrahlung rises smoothly, rolling over as the plasma starts to reach equilibrium. At $3.45 \mathrm{~s}$, when the blooming spot has reached $1550^{\circ} \mathrm{C}$, the slope of the visible bremsstrahlung emission changes. This is shown most clearly in Fig. 9b, the normalized rate of change of the visible bremsstrahlung emission, $\delta \varepsilon / \delta t \varepsilon^{-1}$. The rate of change, which was approaching zero, jumps up. At the same time, there is a change in the slope of the total radiated power (Fig. 9c). From a near stationary value of $6 \mathrm{MW}$ it starts to rise as the carbon influx changes the plasma composition. 
This continues at a constant rate until a second, and very striking, event occurs at $3.78 \mathrm{~s}$. The visible bremsstrahlung radiation and the radiated power both begin to climb very rapidly. At this point, the temperature of the hot spot has reached $2350^{\circ} \mathrm{C}$ (Fig. 9d).

We believe that what has happened here is that at $2300^{\circ} \mathrm{C}$, the simple thermal sublimation yieid of graphite at the damaged site has risen above the RES yield, and is climbing rapidly as the temperature continues to rise. If we examine the behavior of this shot in detail when it is well into the second stage of the bloom, we can make the following observations. At $3.9 \mathrm{~s}, \mathrm{~T}_{\text {(hot spot) }}=2700^{\circ} \mathrm{C}$. Using data for graphite from Langluy (see Sect. 4.3) (Ref. [9], p 55), we calculate an efflux of $\Gamma=2 \times 10^{19}$ atoms-cm $-2-\mathrm{s}^{-1}$. For a hot spot of about $10 \mathrm{~cm}^{2}$, and with 6 electrons per carbon atom, this translates into an electron slux of $1.2 \times 10^{21} \mathrm{~s}^{-1}$. If we look at the increase in the total electron content of the plasma at $3.9 \mathrm{~s}$, we see that it is $1.4 \times 10^{21} \mathrm{~s}^{-1}$. The agreement is fortuitously good. Over the $\pm 50^{\circ} \mathrm{C}$ IR camera error range, the sublimation yield of graphite varies by a factor of 5 , and $10 \mathrm{~cm}^{2}$ is only a guess at the area of the hot spot. Nevertheless, the agreement exists. Furthermore, the temperature behavior of the high temperature bloom is distinctly different from that of the low temperature (RES) bloom.

We conclude that it seems beyond reasonable doubt that the high temperature carbon influx events ( $\mathrm{T}_{\text {hotspot }} \approx 2300^{\circ} \mathrm{C}$ ) are explicable by pure sublimation from limited areas on the graphite limiter, supported by near $100 \%$ recycling of the injected carbon atoms at the limiter surface by physical sputtering. The low temperature carbon blooms $\left(\mathrm{T}_{\text {hotspo: }}=1650^{\circ} \mathrm{C}\right.$ ) are certainly consistent in onset and behavior with radiation enhanced sublimation, and no other likely explanation seems available. In the next section we consider remedies to this situation.

\section{AVOIDING BLOOMS}

In this section we shall describe two modes of running TFTR where the blooms have been delayed or eliminated. We have accomplished this by moving the plasma during beam injection and by increasing the edge density by gas puffing during beam injection. Next, we shall describe the changes we have made to the limiter which have essentially elirninated blooms at power levels up to at least $32 \mathrm{MW}$, the maximum power of our most recent run.

5.1 Plasma Motion A remedy for one spot geting too hot is to move to another spot; neither location then becomes hot enough to bloom. In TFTR, the range of 
plasma motion for large $(a \geq 0.8 \mathrm{~m})$ plasmas is quite limited. During the run period described, the midplane hot spots bloomed at $R=2.45 \mathrm{~m}$, and, at $R=2.6 \mathrm{~m}$, the orgin pipe peretrations bloomed. However, this rangu in $R$ turned out to be enough at the power levels available. By moving the plasma out from $R=2.45 \mathrm{~m}$ to $\mathrm{R}=2.55 \mathrm{~m}$ at a uniform rate during the $1 \mathrm{~s}$ of beam injection, we eliminated the bloom entirely in plasma conditions which produced large blooms on neighboring shots. The outwardly moved plasmas were slightly dirtier and overall performance was not as good; this behavior was connected with target plasma density differences. When we swept the plasma in from $\mathrm{R}=2.6 \mathrm{~m}$ to $2.45 \mathrm{~m}$, the bloom was delayed by $200 \mathrm{~ms}$, and the prebiocin performance was improved over a static shot. As the power is raised, however, from the $26 \mathrm{MW}$ at which ihese experiments were done to the 35 - $38 \mathrm{MW}$ of our current hardware capabiiity, we could not expect this technique to be of sufficient help. Also, a more tender spot on the limiter could develop at the next disruption, which then would bloom at even lowe power fluxes.

5.2 Gas Puffing By artificially increasing the edge density during beam injection, we could hope to accomplish several things which would reduce or eliminate blooming. First, our blooms depend on carbon recycling being $R_{C}=1$ from the entire limiter to keep the carbon evolved from a subliming spot in the plasma. This occurs for fairly high incident energies of the $\mathrm{C}$ ions striking the limiter [12]. If we increase the edge and scrape-off density and thereby cool the ions in it, we could hope to bring $Y_{C}$ down enough to keep the influx from a hot spot from affecting the overal! density and plasma composition. Sputtering yield data taken at an incident ion angle of $70^{\circ}$ suggest that a decrease of $500 \mathrm{eV}$ (from $620 \mathrm{eV}$ to 120 $\mathrm{eV}$ ) would lower the yield from $\mathrm{Y}_{\mathrm{CC}} \approx 1$ to $\mathrm{Y}_{\mathrm{CC}}=0.5$. This is a large change, but increasing the edge density not only reduces the value of $T_{e}$ at a given radius, it also changes the average charge state of the escaping ions. This change in ion energy may be possible to achieve by gas puffing. Second, and probably more important, as the scrapeoff and edge density rise, the low velocity atoms from sublimation will have an increasingly difficult time getting into the plasma core.

During one brief experiment, we puffed $\mathrm{D}_{2}$ into supershots and delayed or eliminated the blooms entirely. We studied gas puffing during a series of $I_{p}=1.6$ MA supershots with $26 \mathrm{MW}$ of injected neutral beam power. With no gas puffs, the shots bloomed reliably after $500 \mathrm{~ms}$ of beam heating. We then injected $\mathrm{D}_{2}$ gas from one of our normal gas feed nozzles (located at the top of the vacuum vessel) at the 
rate of 70 torr-liters-s ${ }^{-1}$. This is about $5.0 \times 10^{21}$ atoms-s ${ }^{-1}$, compared to $3.6 \times 10^{21}$ atoms $-s^{-1}$ from $D$ recycling at the plasma edge and $2.2 \times 10^{21}$ atoms-s -1 of core fuelling by the neutral beams. We injected the gas $250 \mathrm{~ms}$ after the beam injection began to allow the characteristic supershot profile to be established. (For a detailed discussion this work, see ref. [20].) Blooming was completely suppressed. $\mathrm{A} \mathrm{C}^{+4}$ influx line showed a reduction of $25 \%$ in intensity, which supports the idea that global carbon recycling was suppressed. The total radiated power also dropped. The

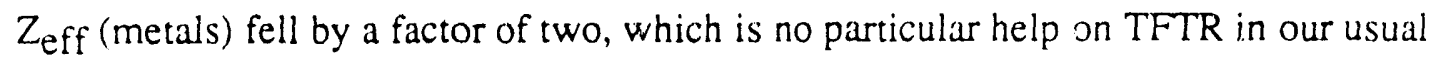
operating conditions, but could be very important elsewhere, and further supports the idea that the edge temperature was lowered. Probably because of lower carbon content in the plasma, the neutron production rate for successful gas puffing shots is higher than the average for a good supershot without puffing. One of the highest $Q$ shots on TFTR was produced with gas puffing.

The injection of just enough gas into a supershot is a difficult baiancing act, and it does not always work. We know that strong limiter pumping is necessary to produce the peaked density profile of the supershot. The gas puffing not only reduces limiter pumping, but tends to raise the density at the plasma edge, which affects the fuelling and heating of the core. Nevertheless, the performance of successful gas puffing shots is so good that we plan more work with edge modification experiments, both to reduce the tendency to bloom and to produce a cleaner target plasma.

5.3 New Limiter Material We have been using POCO ${ }^{\mathrm{TM}}$ type AXF-5Q graphite as the limiter material. A disadvantage of this graphite is its response to catastrophic heat loads. The surface spalls, leaving flakes of graphite only loosely attached to the underlying limiter. These flakes not only produce blooms when the power is high enough, but dirty plasmas for even modestly heated discharges. For these reasons we replaced the midplane tiles with new tiles made of a 4-directionally woven carbon-carbon composite; the new material is manufactured by Fiber Materials Incorporated. The central 6 tiles on the midplane were replaced everywhere, with an additional 6 ( 3 above and 3 below) added at the center of each bay where higher heat loads occur. Laboratory tests have shown that this material is much more resistant to flaking than POCO'M [21], and we hoped that disruptions on the new material would not cause the damage we have seen on the POCO ${ }^{\mathrm{m}}$.

The 1990 run period which followed installation of the new tiles was only 7 months long, but we had more than 7000 high power discharges. There were 90 disruptions during the current flattop, of which 20 occurred during beam injection. 
In addition, there were a number of disruptions during current rampdown at the end of the discharge, some of which affected following plasmas as strongly as flattop disruptions. After the run, we inspected the inside of the vacuum vessel. There was not one damage site with carbon flakes, and not one of the new tiles had cracked. During this run we had shots with $30 \mathrm{MW}$ of neutral injected power for $1 \mathrm{~s}$ which did not bloom, nor did shots with $23 \mathrm{MW}$ which lasted for $2 \mathrm{~s}$. The few carbon blooms we saw in this run were not repeatable, and had the character of clean-up blooms; that is, blooms from chips and flakes left over from installation which burned away as we beam-conditioned the limiter.

5.4 Limiter Re-Alignment The limiter tiles in TFTR are mounted on a series of backing plates. To allow for thermal expansion while keeping the stress at a safe level, 3 of the 4 mounting holes in the backing plates are enlarged in at least ont dimension to allow motion. We believe that instead of sliding freely under thermal expansion, some of the backing plates have been binding. In a series of heating and cooling cycles, some plates appear to have ratcheted into a misaligned condition. The pair of tiles which became offset in Bay I and produced our a major bloom site are a possible example of this. Bulk limiter temperature measurements were consistent with the midplane position of one tile backing about 1 to $2 \mathrm{~mm}$ higher than the adjacent non-slipping plate, and examination of the limiter after the run verified this. (We should note here that $\pm 2 \mathrm{~mm}$ was the original TFTR specification for limiter alignment accuracy.)

As a remedy, we clamped all four comers of the backing plate down so tightly that no motion is possible. Detailed stress analysis encouraged us in the belief that even our most severe thermal loading would produce stress within acceptable limits. Examination after the run showed that most of the slippage and resulting misalignment had been eliminated. At the one location where a plate had become raised, the exposed tile edges had been burnished by power loading, but no damage had resulted.

5.5 Limiter Re-Shaping Finally, having taken steps to eliminate high or hot spots due to damage and limiter slippage, we were left with those hotspots due to limiter design. At every place where there is a recess in the limiter, there is a conjugate location which must take the power that would have been deposited on the recessed area. Such recesses in TFTR are mirrors, viewing dump:, and diagnostic access holes. We know that the access holes ("organ pipes") bloomed at $28 \mathrm{MW}$ when we ran large plasmas which have high heat loads at those locations. We 
modified the tiles around the organ pipes. Rather than being simple cylindrical penetrations with $90^{\circ}$ edges, the edges are beveled to extend the load over an area comparable with the hole itself. Calculations indicated that the resultant temperature rise will be within tolerable levels even at much higher input power than we presently can produce. The reworked tiles were installed during the opening before the 1990 run.

We operated at $R \approx 2.6 \mathrm{~m}$ during the last run at power levels greater than those that produced blooms before, and only a few transient events were seen. However, inspection of these tiles revealed that one of them cracked during the run; we believe thermal stress at a mounting groove from high power operation at $R=2.6 \mathrm{~m}$ was responsible. This site could have worsened and become a bloom site in a longer run. The broken tile will be replaced with a carbon composite one.

\section{CONCLUSIONS}

We have argued that the carbon blooms observed in supershots on TFTR are caused by sublimation from damaged spots at or near the last closed flux surface. For the blooms whose onset is observed at $1650 \pm 150^{\circ} \mathrm{C}$, the evidence is consistent with the mechanisms of radiation enhanced sublimation described by Roth and others. At temperatures of about $2300^{\circ} \mathrm{C}$, an additional influx is noted in the bloom, and yields from ordinary physical sublimation are consistent with the observed density rises. In both cases, we believe that a carbon-carbon sputtering yield of ${ }{ }_{C C}$ $\approx 1$ is acting to keep the sublimed carbon in circulation long enough to cause the damaging density rise and plasma dilution which are characteristic of blooms (see the Appendix).

Techniques for delaying or avoiding blooms by moving the plasma to distribute the heat load work only at current power levels. Edge cooling techniques to lower the sputtering and sublimation are more promising as a general approach, but require a very delicate touch to attain good supershot performance.

Finally, we modified the TFTR bumper limiter. This involved changing limiter material to a carbon composite, preventing thermaily induced static misalignment of the limiter backing plates, and modifying the tiles with sharp edges following holes which heat up. These changes eliminated blooming at the $30 \mathrm{MW}$ level, and we believe will continue to be effective at the ultimate power levels planned for TFTR. 


\section{ACKNOWLEDGMENT}

This work was supported by U. S. Department of Energy Contract No. DE-AC02-76-CHO-3073. 


\begin{abstract}
APPENDIX
In several places in this paper, we have made rough calculations or presented arguments which assumed that global carbon recycling is essentially $100 \%$; for every carbon ion that leaves the plasma core, another enters. In this appendix, we attempt to justify that assumption.

Reliable data on carbon-carbon sputtering for grazing incidence is lacking, as is information about the energy distribution of the sputtered particles on which plasma penetration depends. Extrapolations anci the use of sputtering models have led some observers to wonder if we are not close to a run-away situation, particularly for the specific case of the TFTR edge parameters and magnetic limiter geometry $[11,10]$. (See also the general discussions of this problem in Refs. [12, 22, 23].) Detailed edge modeling of this regime is being done by several groups.

Here, we shall use simple arguments and $Z_{e f f}$ and density data to show that carbon recycling is $R_{C} \approx 1$. In supershot target plasmas, the only major impurity is carbon, so that we may deduce the core carbon density from the $\mathrm{Z}_{\text {eff: }}$ :
\end{abstract}

$$
\mathrm{Z}_{\mathrm{eff}}=\frac{\mathrm{n}_{\mathrm{D}}}{\mathrm{n}_{\mathrm{e}}}+36 \frac{\mathrm{n}_{\mathrm{C}}}{\mathrm{n}_{\mathrm{e}}}
$$

We take this as a global measure, since we have never seen any significant radial dependence of $Z_{e f f}$ in supershots. Thus, we are able to calculate the rate of change of the total carbon content of the plasma from $Z_{e f f}(t)$ and $N_{e}(t)$ :

$$
\frac{\delta N_{C}}{\delta t}=\frac{\delta N_{e}}{\delta t}\left(\frac{Z_{e f f}-1}{30}\right)+\frac{\delta Z_{\mathrm{eff}}}{\delta t}\left(\frac{N_{e}}{30}\right)
$$

The global continuity equation for carbon, including carbon-carbon and deuteriumcarbon source terms is

$$
\frac{\delta N_{C}}{\delta t}=\frac{N_{C}}{\tau_{C}} Y_{C C}+\frac{N_{D}}{\tau_{D}} Y_{D C}-\frac{N_{C}}{\tau_{C}}
$$

Here we have implicitly assumed that the penetration efficiency of sputtered carbon getting into the core is $100 \%$. This is probably not far from the truth. A detailed 
calculation by Stangeby and Farrell for the JET limiter gives a global efficiency of $75 \%$. The calculation uses an effective sputtered energy of the carbon atoms lowered substantially by the contributions from the YDC yield [22]. Both the higher energy of the $\mathrm{Y}_{\mathrm{CC}}$ products and the TFTR geometry will increase this number.

Since we know the change in $\mathrm{N}_{C}$ from Eqn. $A 2$, we can calculate $\mathrm{Y}_{\mathrm{CC}}$ if we know YDC:

$$
\mathrm{Y}_{\mathrm{CC}}-1=\frac{\delta N_{\mathrm{e}}}{\delta \mathrm{t}} \frac{\tau_{\mathrm{p}}}{\mathrm{N}_{\mathrm{e}}}+\frac{\delta \mathrm{Z}_{\mathrm{eff}}}{\delta \mathrm{t}} \frac{\tau_{\mathrm{p}}}{\mathrm{Z}_{\mathrm{eff}}-1}-\mathrm{Y}_{\mathrm{DC}} \frac{6\left(6-\mathrm{Z}_{\mathrm{eff}}\right)}{\mathrm{Z}_{\mathrm{eff}}-1}
$$

For YDC we shall use the value from Stangeby and Farrell's calculation for JET: $Y_{D C}=0.030$. Taking the data from the ohmic phase of the RES bloom shot discussed in Sect. 4.5 and shown in Figs. 6, 7, and 8, we find $\left(\delta \mathrm{N}_{\mathrm{e}} / \delta t\right) \mathrm{N}_{\mathrm{e}}^{-1}=-0.018$ $\mathrm{s}^{-1},\left(\delta \mathrm{Z}_{\text {eff }} / \delta \mathrm{t}\right)\left(\mathrm{Z}_{\text {eff }}-1\right)^{-1}=-0.03 \mathrm{~s}^{-1}$. The shot was almost in equilibrium just before the beams came on. $Z_{\text {eff, when corrected for the metal contribution, was }}$ $\mathrm{Z}_{\mathrm{eff}}=5.7$. For the particle confinement time, we shall use half the energy confinement time of $\tau_{E}=0.13 \mathrm{~s}$. (Heifetz has found this to be a reasonable value for deuterium ohmic confinement times from extensive modeling of TFTR plasmas using DEGAS and absolutely measured $\mathrm{H}_{\alpha} / \mathrm{D}_{\alpha}$ brightness profiles [24].) Examining the contributions of each term in Eqn. A4, we see that the major factor is the deuterium-carbon sputtering term. We find for this shot that $Y_{C C}=0.99$; allowing $\mathrm{Y}_{\mathrm{DC}}$ to increase by $50 \%$ gives $\mathrm{Y}_{\mathrm{CC}}=0.98$. The largest uncertainty in $\mathrm{Y}_{\mathrm{CC}}$ arises from the uncertainty in the $\mathrm{Z}_{\text {eff }}$ value. If we let $\mathrm{Z}_{\text {eff }}$ take its $1 \sigma$ lower bound, we get $\mathrm{Y}_{\mathrm{CC}}=0.96$.

W: conclude, then, with the result that the carbon self-sputtering yield for this shot is $Y_{C C}=0.99_{0.03}^{+0.01}$ with the simplifying assumptions used. We should recall that $Y_{C C}$ depends on the amount of deuterium dissolved in the limiter. Brooks, using data from a TFTR limiter de-conditioning scan and the REDEP/MEASTRI codes, has calculated a decrease in $\mathrm{Y}_{\mathrm{CC}}$ of more than $30 \%$ as the deuterium level in the carbon approaches saturation [10]. The limiter was well conditioned for this shot, and we would expect $Y_{C C}$ to be near its maximum value. Our result supports the assumptions made in the calculations of the effect of influx from local hot spots on the plasma content. It also explains why a bloom at any location near the LCFS results in a large increase in carbon recycling over the entire limiter surface, as we have observed. 


\section{References}

11) Strachan, J. D., Bitter, M., Ramsey, A. T., Zarnstorf, M. C., Arunasalam, V., et al., Phys. Rev. Lett. 55 (1987) 1004.

(2) Ulrickson, M., J. Nucl. Mat. 176 \&177 (1990) 7.

[3] Roth, J., Bohdansky, J., Wilson, K. L., J. Nucl. Mat. 111-112(1982) 775.

14) Ramsey, A. T., Hill, K. W., Stratton, B. C., Synakowski, E. J., Zarnstorff, M. C., (to be published)

[5] Ramsey, A. T., Tumer, S. L., Rev. Sci. Instrum. 58 (1987) 1211.

[6] Pitcher, C. S., McCracken, G. M., Stangeby, P. C., Allen, J., Fielding, S. J., et al., J. Nucl. Mat. 145-147 (1987) 539.

[7] Medley, S. S., Dimock, D. L., Hayes, S., Long, D., Lowrance, J. L., et al., Rev.Sci.Instrum. 56 (1985) 1873.

[8] Barnes, G. W., Owens, D. K., Loesser, G. D., Ulrickson, M. 13th symposium on Fusion Engineering, Ed. M. S. Lubell, M. B. Nestor, S. F. Vaughan, 2 vols IEEE, New York 1990, 1:937

[9] Langley, R. A., Bohdansky, J., Eckstein, W., Mioduszewski, P., Roth, J., et al., Nuc. Fusion Supplement (1984)

[10] Brooks, J. N., Brice, D. K., DeWald, A. B., McGrath, T. T., J. Nucl. Mat. 162164 (1989) 363.

[11] Brooks, J.,personal communication, March, 1988.

[12] Roth, J., Bohdansky, J., Ottenberger, W., J. Nuc. Mat. 165 (1989) 193.

[13] Ramsey, A. T., Stratton, B. C., Boody, F. P., Bush, C. E., Dylla, H. F., et al., J. Nuc. Mat. 145-147 (1987) 592.

[14] Vietzke, E., Flaskamp, K., Hennes, M., Philipps, V., Nuc. Instrum. Meth. B2 (1984) 617.

[15] Roth, J., Möller, W., Nucl. Instr. and Meth. B7/8 (1985) 788.

[16] Bohdansky, J., Roth, J. The 15 th Symposium on Fusion Technology. Ed. A. M. van Ingen, A. Nijsen-V'is and H. T Klippel. 2 vols. Fusion Technology. Utrecht: North-Holland, 1988. 1: 889.

[17] Stratton, B. C., Fonck, R. J., Ramsey, A. T., Synakowski, E. J., Grek, B., et al., Vucl. Fusion 30 (1990) 675.

(18) Mansfield, D. K., Park, H. K., Johnson, L. C., Anderson, L. C., Chouinard, R., 
et al., Appl. Optics 15 (1987) 4469.

[19] Nygren, R. E., Bohdansky, J., Pospieszczyk, A., Lehmer, R., Ra, Y., et al., J. Vac. Sci. Technol. A 8 (1990) 1778.

[20] Bush, C. E., to be published in J. Vac. Sci. Tech.

121) Dylla, H. F., Ulrickson, M. A., Owens, D. K., Heifetrz, D. B., Mills, B. E., et al., J. Nuc. Mat. 155-157 (1988) 15.

[22| Stangeby, P. C., Farrell, C., Plasma Phys: Cont. Fusion 32 (1990) 677.

[23] Brooks, J. N., J. Nucl. Mat. 170 (1990) 164.

[24] Heifetz, D. H., Ehrhardt, A. B., Ramsey, A. T., Dylla, H. F., Budny, R., et al., J. Vac. Sci. Technol. A 6 (1988) 2564. 


\section{Figure Captions}

Fig. 1 Poloidal profiles of $\mathrm{C}^{1+}$ and $\mathrm{D}_{\alpha}+\mathrm{H}_{\alpha}$ emission during a shot which bloomed. Both arriys view the upper half plane at the same toroidal location. The TFTR bumper limiter extends $\pm 60^{\circ}$ from the midplane; the last channel of both ariays views just past the edge of the limiter. Figure la shows the carbon array data. The bloom begins at 4 seconds, and the profile peak shifts upward slightly as it increases. Figure $1 b$ shows the $D_{\alpha}+H_{\alpha}$ signal on the same scale. Note that this profile changes quite sharply, going from slightly peaked to quite hollow during the bloom. The units are surface brigheness, photons/( $s-\mathrm{cm}^{2}-9$. -steradian) .

Fig. $2 Z_{\text {eff }}$ and carbon density of a bloom. Neutral injection begins at 3.0 seconds for this shot, and $\mathrm{Z}_{\text {eff }}$ falls as the deuterium beams dilute the plasma core. At $3.4 \mathrm{~s}$, the bloom begins and $Z_{\text {eff }}$ climbs as carbon evolved from the wall penetrates to the plasma core. Figure $2 b$ shows the line-average carbon density from Eq. 1. The small drop at $3.0 \mathrm{~s}$ is due to decreased $\mathrm{C}$ penetration into the plasma as the edge density rises. By the time the beams turn off, the plasma is primarily a carbon one.

Fig. 3 Effects of a bloom on stored energy and neutron production are shown for a shot that bloomed at $3.9 \mathrm{~s}$. Neutral injection lasted from $3.5 \mathrm{~s}$ to $4.5 \mathrm{~s}$ at a constant level of $30 \mathrm{MW}$. Figure $3 \mathrm{a}$ shows the rise in midplane $\mathrm{C}^{1+}$ emission at the limiter, and Fig. $3 \mathrm{~b}$ shows the line integrated density from a vertical FIR interferometer sightline at a major radius of $1.8 \mathrm{~m} \mathrm{[18].} \mathrm{The}$ plasma center was at $\mathrm{R}=2.45 \mathrm{~m}$, and the limiter major radius at the midplane is $1.65 \mathrm{~m}$. Neutron production, Fig. 3d, falls immediately, and the stored energy, Fig. 3c, rolls over shortly after.

Fig. 4 The $\mathrm{C}^{1+}$ array viewing a bloom site directly. The sightline of the third channel up from the midplane overlaps the poloidal elevation a hole in the limiter; the two are separated toroidally by no more than a few centimeters. The hot edge of this hole is the source of the bloom. 
Fig. 5 Rise in bulk limiter temperature divided by total energy to the limiter for each bay of the TFTR torus. The three hot bays (I, M, and R) indicate where the limiter had slipped out several millimeters and were subjected to higher power loading as a result. The Bay $B$ top hot spot is caused by a recess at Bay $C$, so that Bay B top is receiving part of that power, too.

Fig. 6 Time rate of change of the tota! electron content of the plasma for a low temperature (RES) bloom. Neutral injection begins at $3.0 \mathrm{~s}$. The bloom begins just before $3.6 \mathrm{~s}$, after the density has reached equilibrium. The increase in density remains approximately constant through the bloom.

Fig. 7 Temperature of the bloom site for the bloom of Fig. 6. The blcom onset is $3.6 \mathrm{~s}$, when the surface temperature of the bloom site is $15000^{\circ} \mathrm{C}$. Note that the temperature continues to rise through the bloom until after the neutral beam heating shuts off.

Fig. 8 Ion temperature at the plasma edge during a bloom. Neutral injection begins at $3.5 \mathrm{~s}$, and the bloom begins at $4.0 \mathrm{~s}$. This temperature is from Doppler broadening of a simple component of the intermediate field Zeeman multiplet of $\mathrm{C}^{1+}$ at $6580 \AA$. It is measured on the midplane with a radial view looking directly at the limiter. Since the LCFS for a supershot at $\mathrm{R}=2.45 \mathrm{~m}$ is tangent to the limiter at the midplane, the temperature measured is in the plasma core and not in the scrapeoff.

Fig. 9 Bloom which begins with RES and continues to pure thermal sublimation. Figure 9a shows the visible bremsstrahlung emission from a horizontal midplane sightline tangential to the limiter. The RES bloom begins at $3.45 \mathrm{~s}$; the sublimation bloom at $3.78 \mathrm{~s}$. Figure $9 \mathrm{~b}$ shows the normalized time derivative of Fig. $9 \mathrm{a}, \delta \varepsilon / \delta \mathrm{t} \varepsilon^{-1}$. Here the bloom onsets are clearer. The drop at $3.6 \mathrm{~s}$ is a sawtooth crash. Figure $9 \mathrm{c}$ shows the total radiated power. Figure $9 \mathrm{~d}$ shows the temperature of the hot spot which was blooming. 

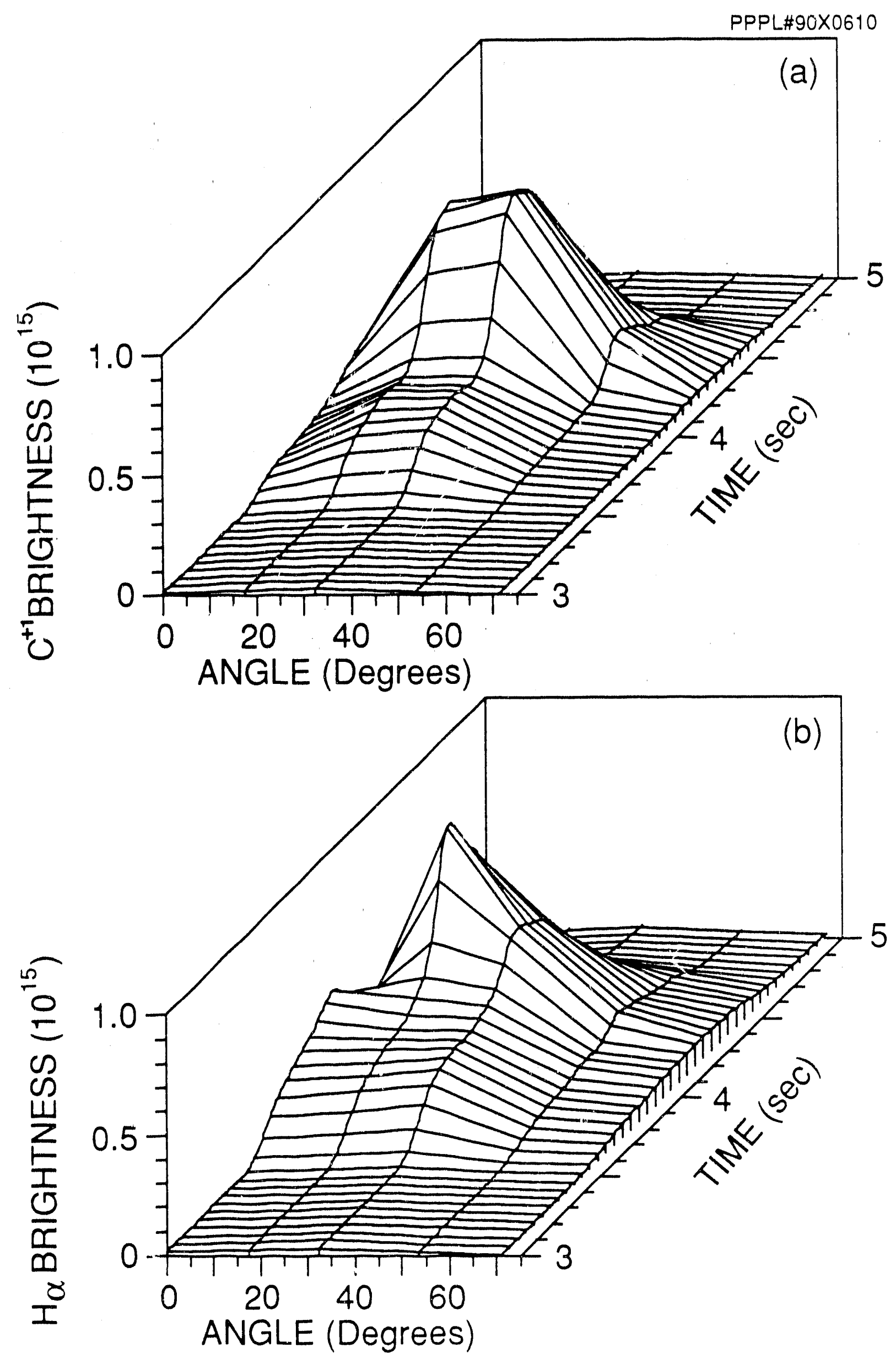

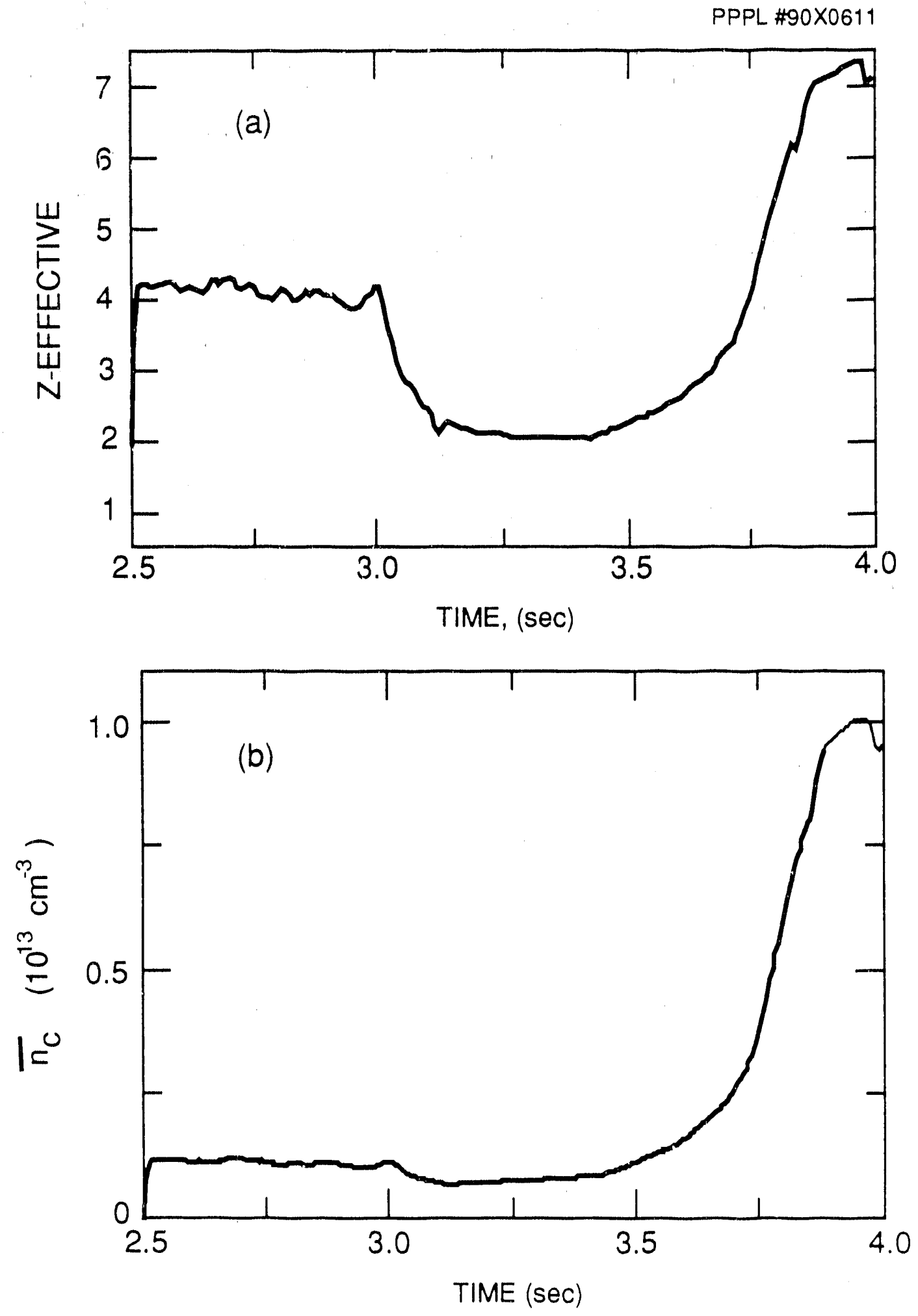

Fig. ? 

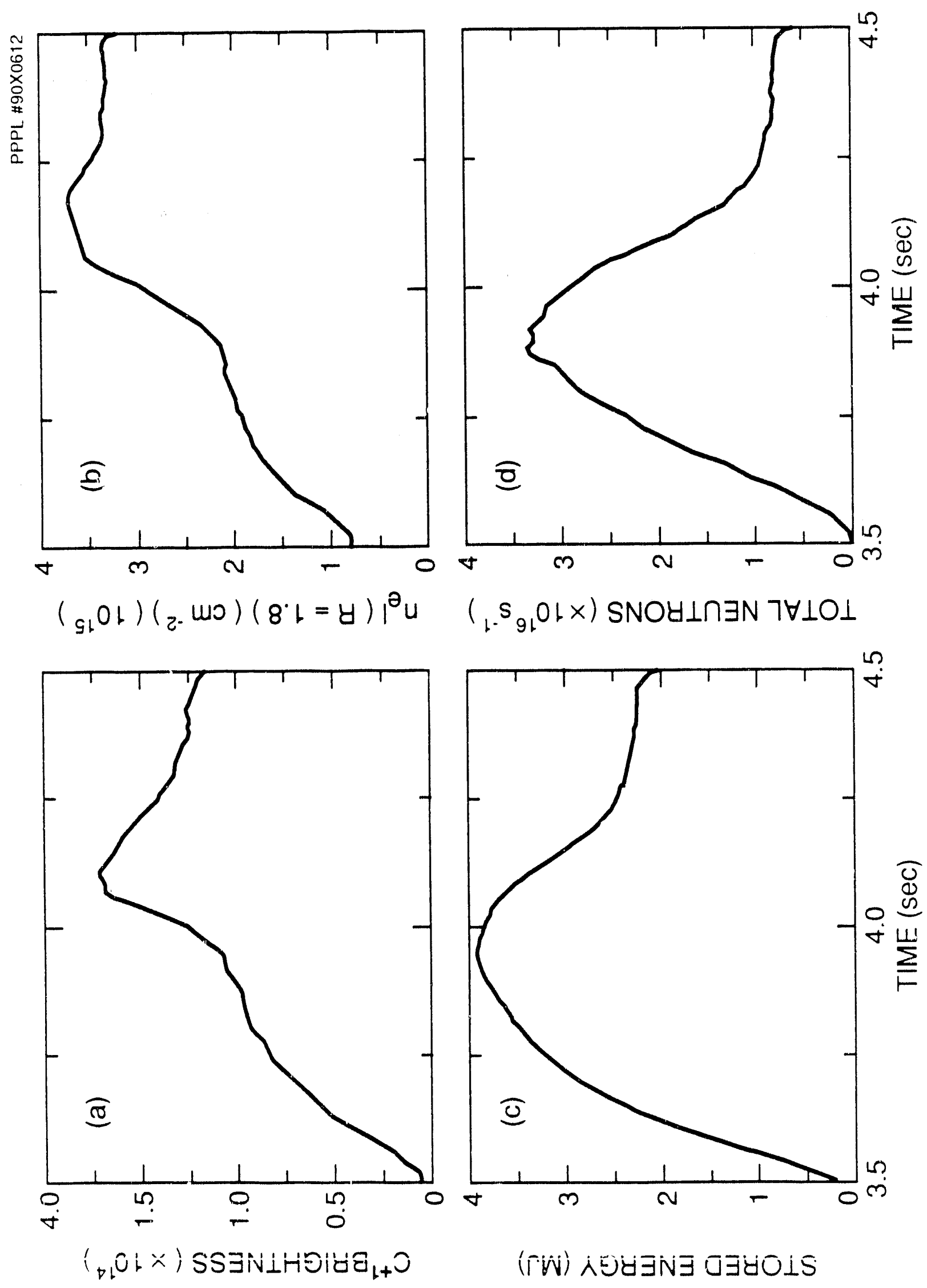

$\left(s_{b l} O L X\right) S N O H \perp \cap \exists N 7 \forall \perp O \perp$

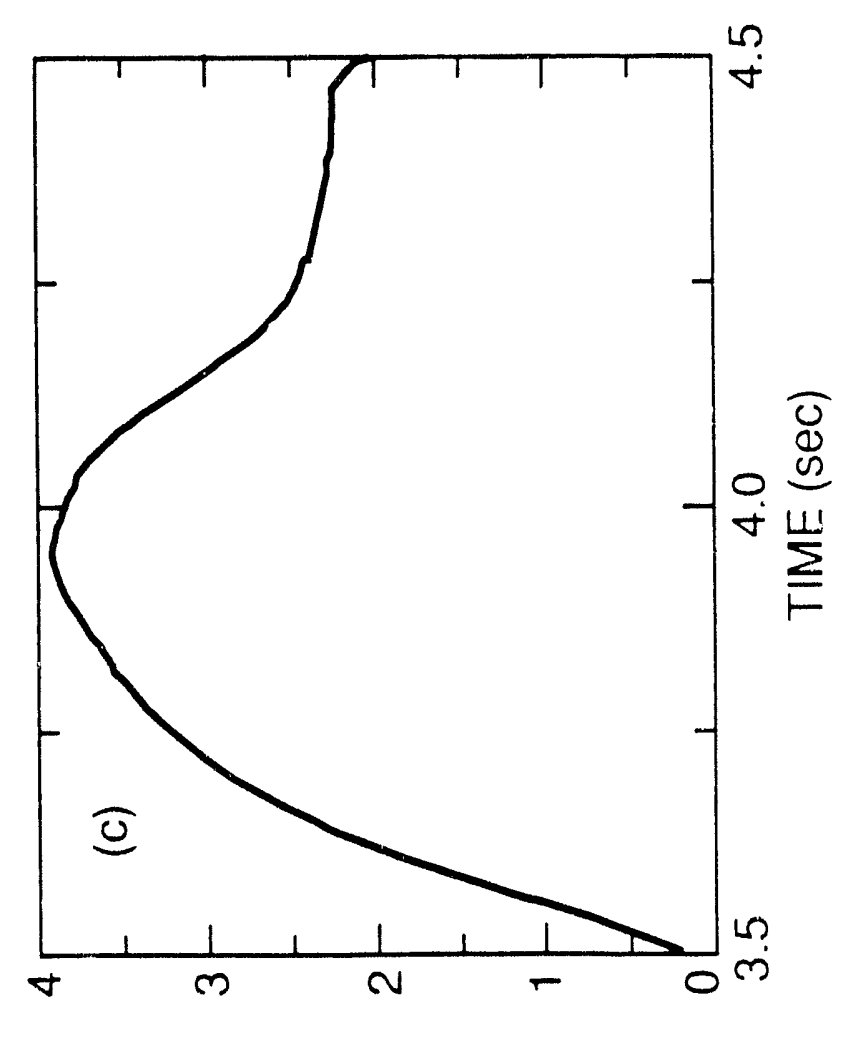

(กเท่) 


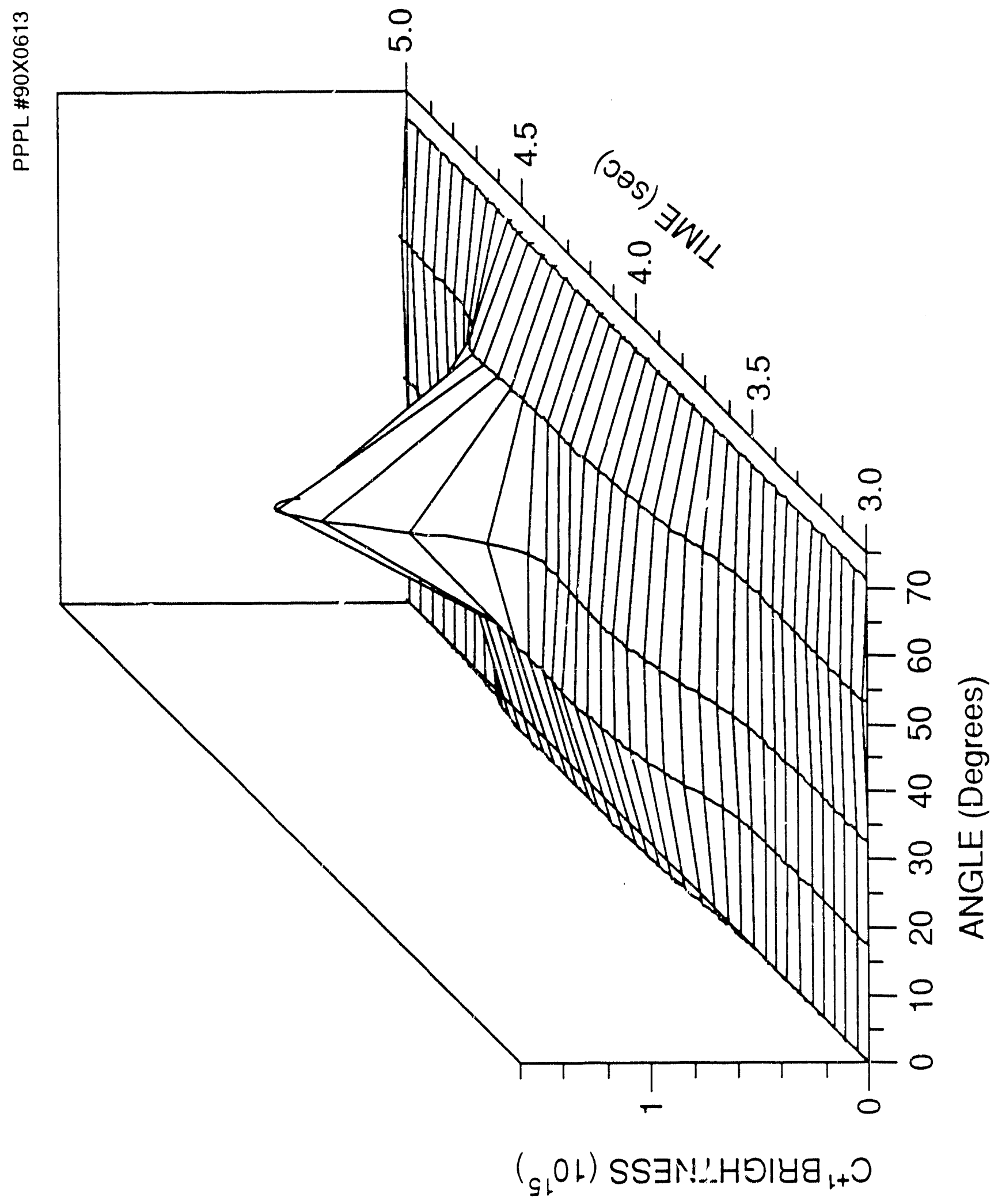

$\dot{x}$ 


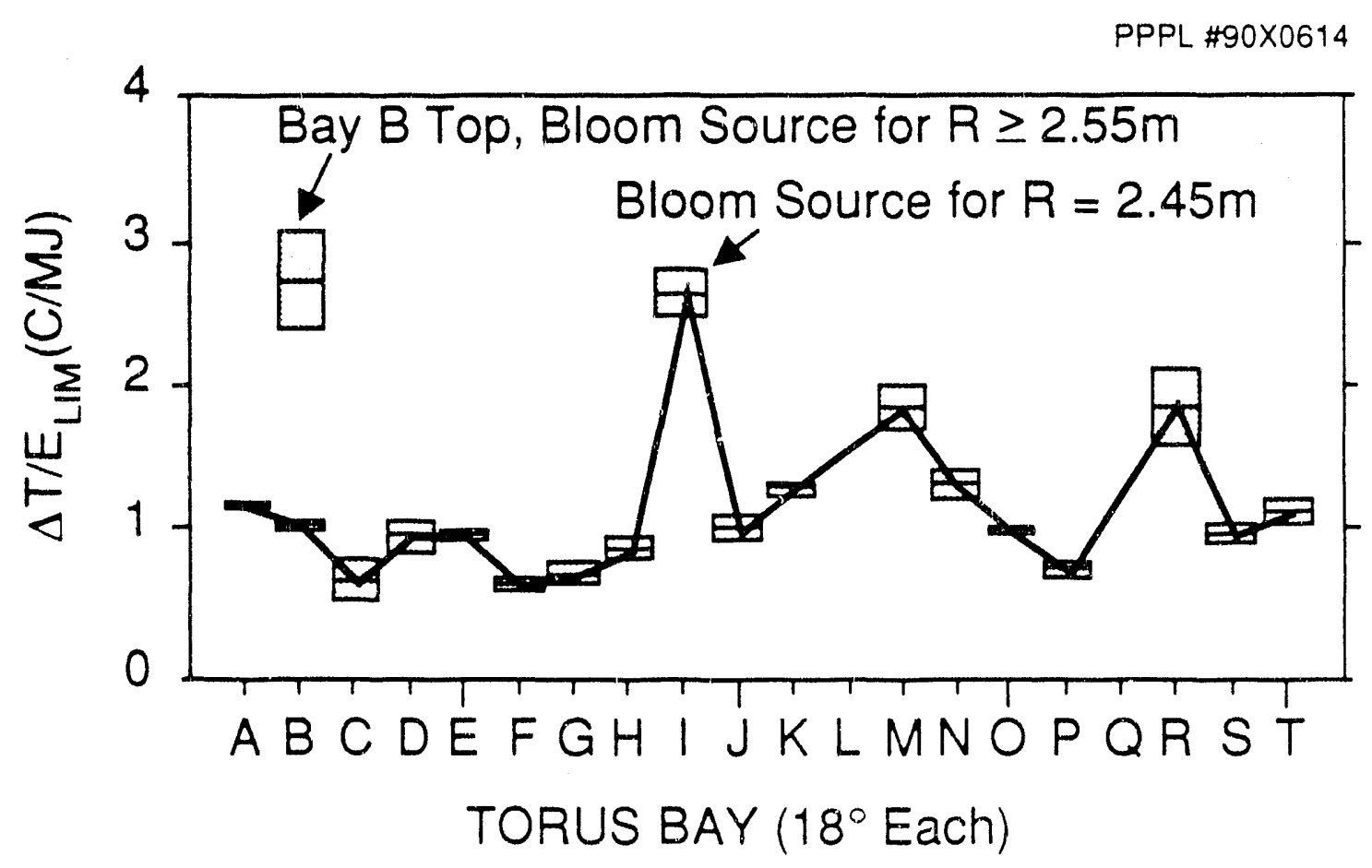




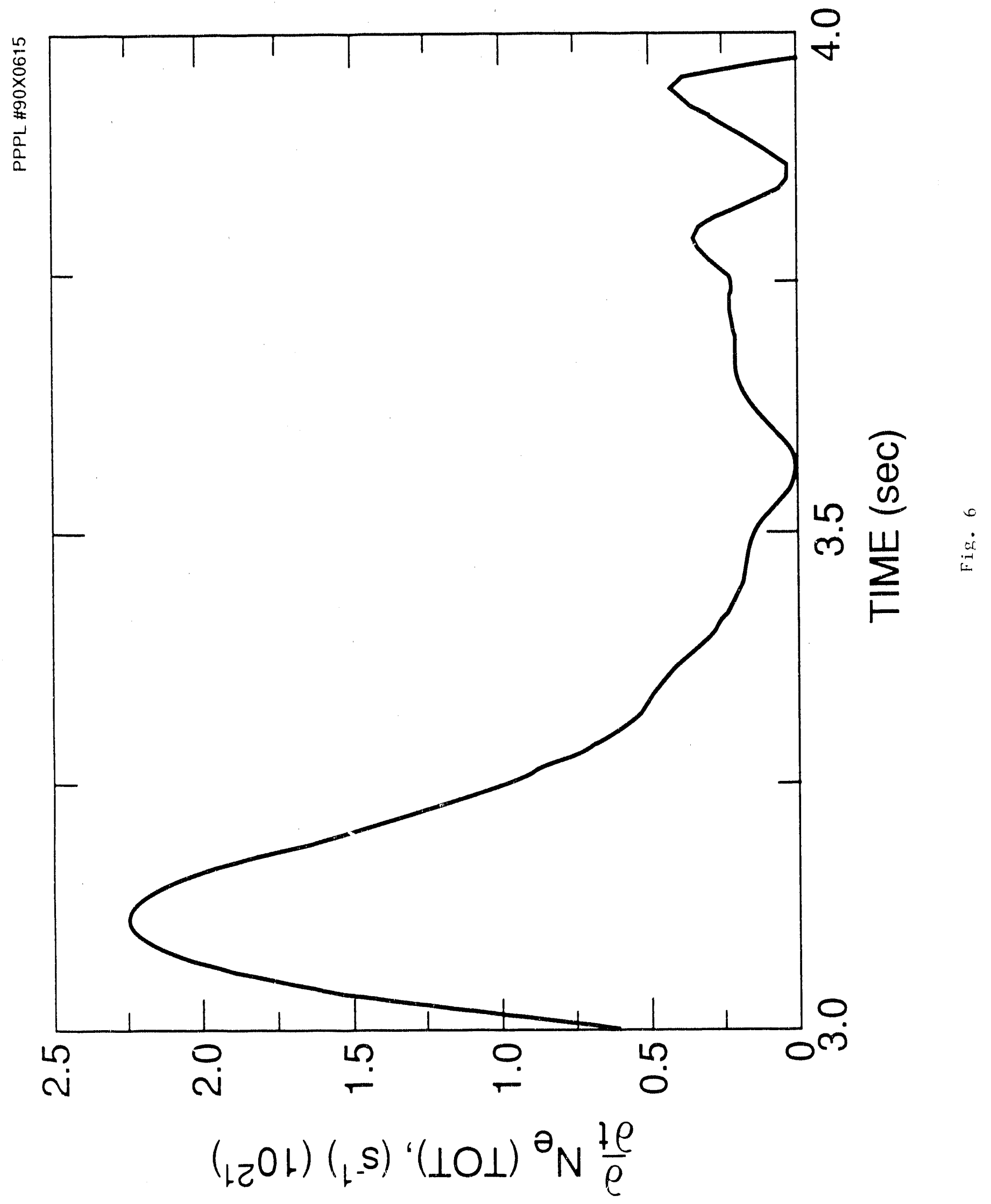




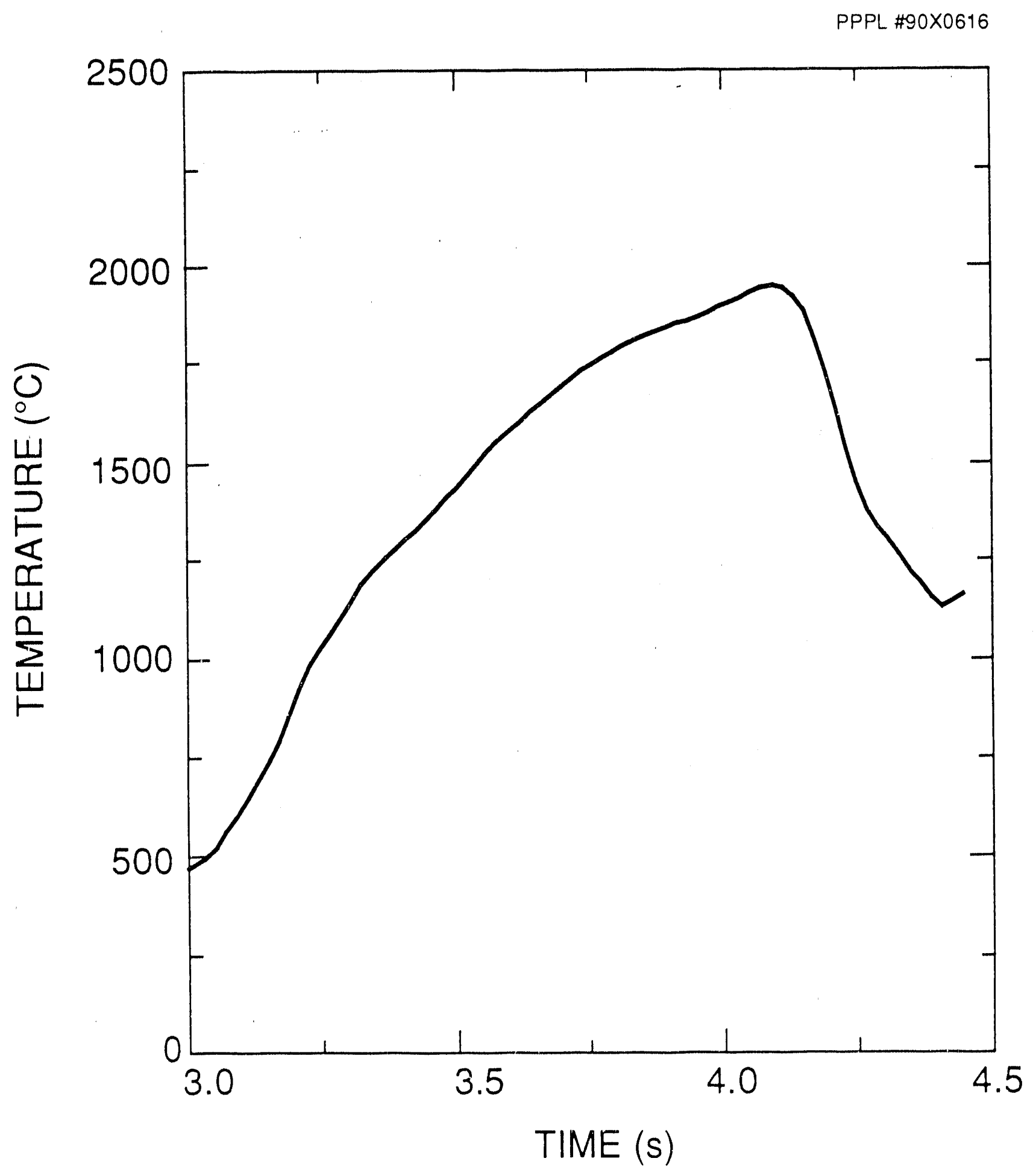

Fio. 


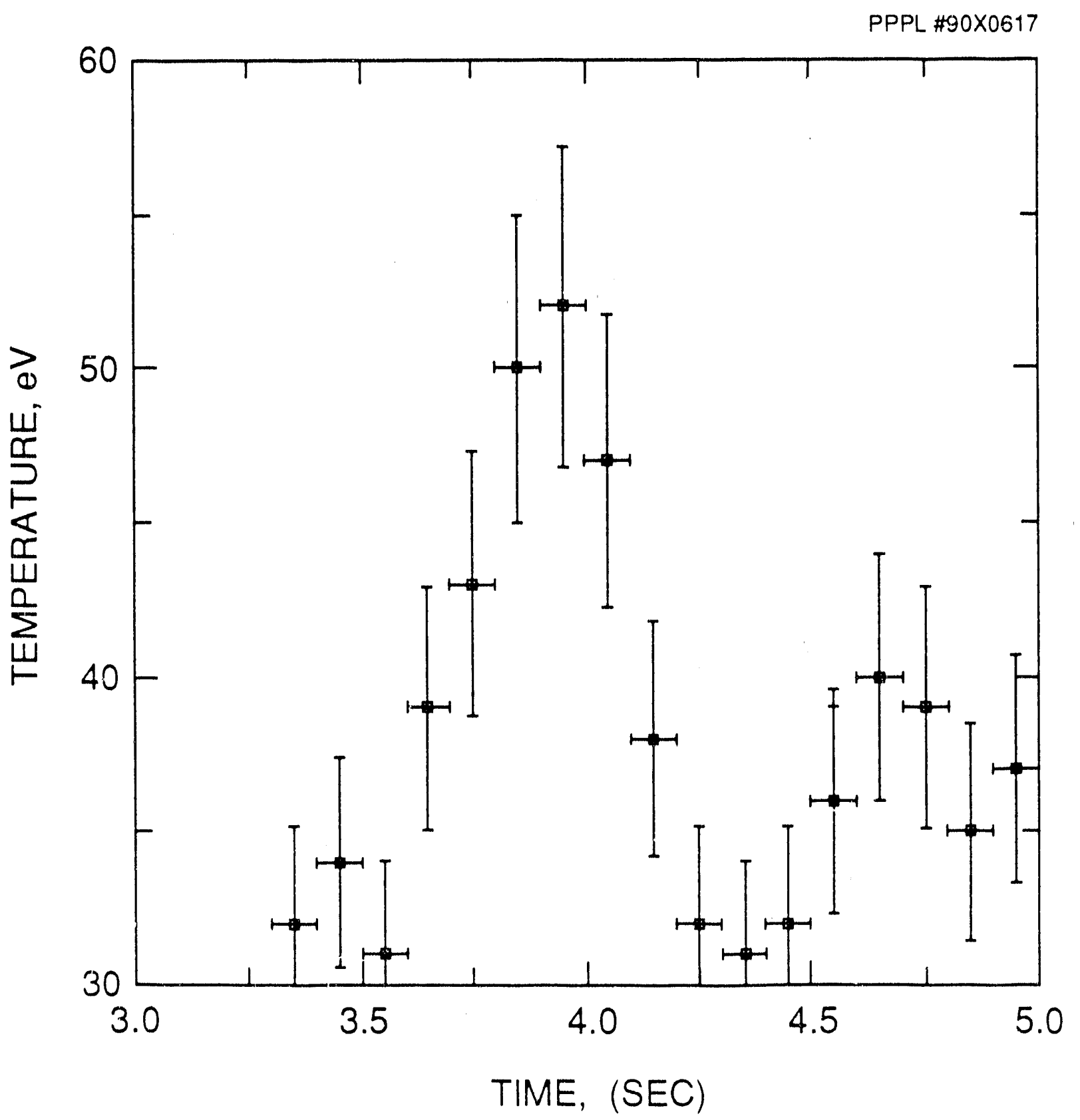



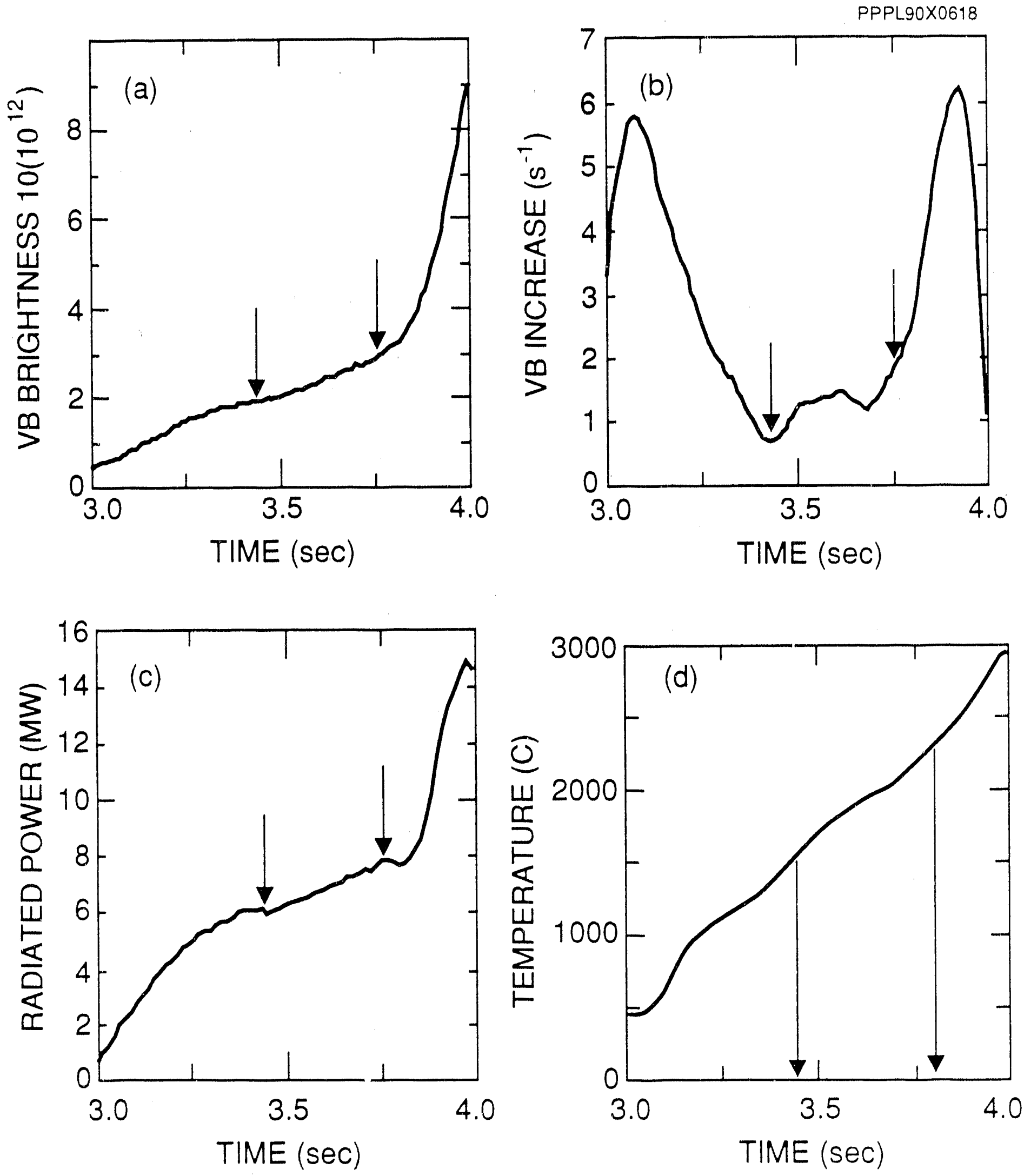

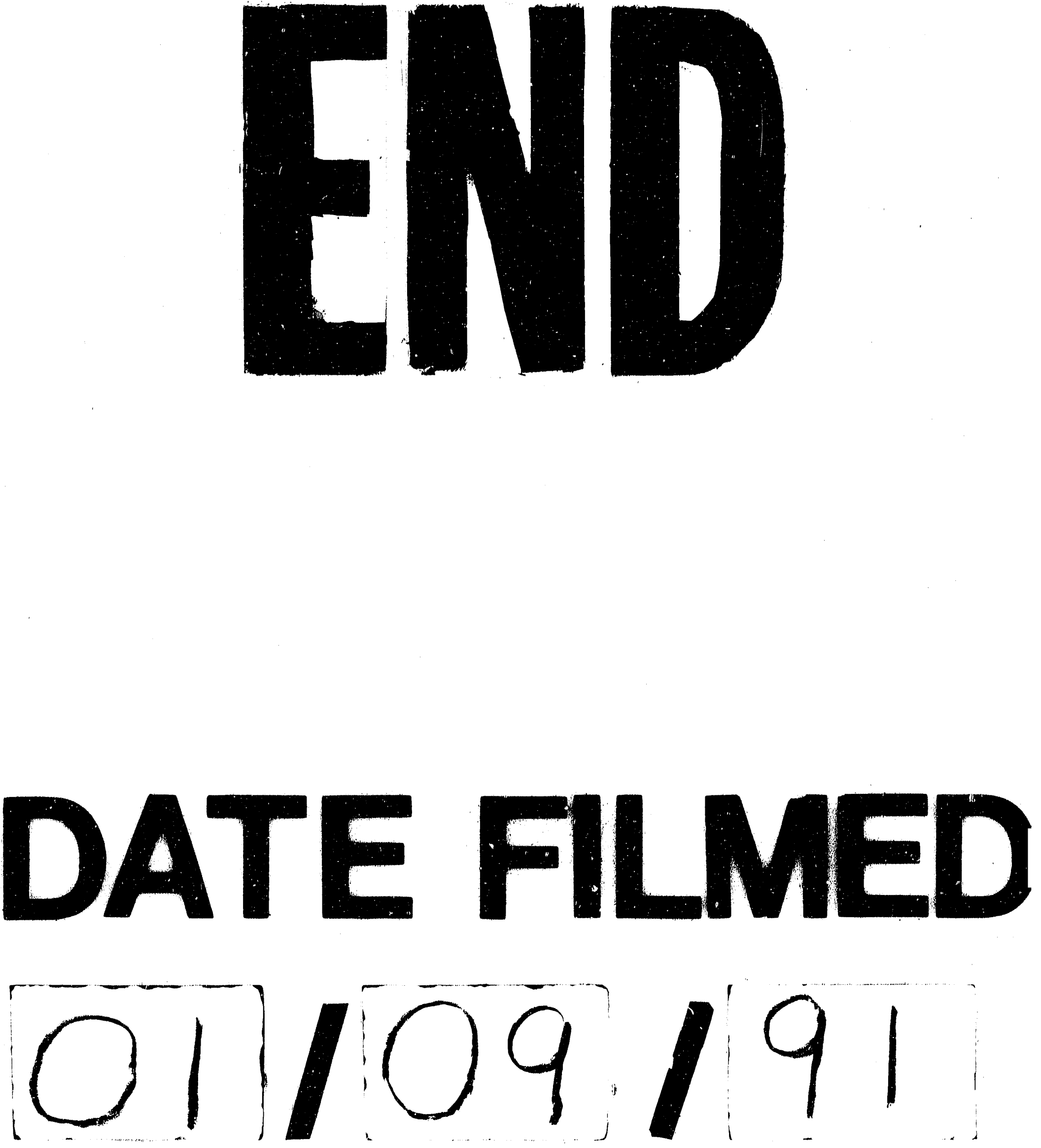
